\title{
The implementation of chairside talk regarding plaque control instruction by Periodontics Residents
}

\author{
Anggun Rafisa*, Gilang Yubiliana*, Asty Samiaty Setiawan* \\ *Department of Community Dentistry Faculty of Dentistry Universitas Padjadjaran
}

ABSTRACT

The effort to educate patients regarding oral health maintenance can be performed through the chairside-talk. The purpose of this study was to observe the chairside-talk implementation regarding the plaque control instruction by Periodontics Residents of the Periodontics Clinic Faculty of Dentistry Universitas Padjadjaran Dental Hospital, Bandung, Indonesia. This study was a descriptive study with a survey technique. All data were collected using a checklist sheet. The results showed that $100 \%$ of residents were performing chairside-talk about plaque control instruction. As much as $86.3 \%$ from all residents performed the way of communication based on the literature's recommendation, $81.67 \%$ preferred to teach the patient about toothbrushing directly, and $78.64 \%$ gave a direct plaque control instruction. All residents were performing the chairside-talk regarding the plaque control instructions, where the majority of them were performing the way of communication by literature recommendation, and the rest were preferred a direct toothbrushing teaching and plaque control instruction.

Keywords: Chairside talk, Periodontics Residents, plaque control instruction.

\section{INTRODUCTION}

Indonesia Basic Health Research (RISKESDAS) in 2007 showed that the prevalence of the oral problems in Indonesia was $23.4 \%$. About 19 provinces have a prevalence of oral problems above the national prevalence, and West Java was among them. The percentage of the population of the 10-years-old age group in Indonesia who did the toothbrushing was high enough (91.1\%). However, only $12.6 \%$ of them were brushing their teeth after breakfast, $28.7 \%$ before bedtime, and only $7.3 \%$ brush their teeth in properly. Based on this research, we can see that the knowledge of the people about the maintenance of oral health is still very low so that the dental health promotion needs to be improved. ${ }^{1}$

Health promotion is not only necessary for preventive and promotive services but also necessary for curative and rehabilitative services, and also hospital services. ${ }^{2}$ Dentists are able to do the health promotion in the hospital.

Dentists must teach a patient or a group of patients about how to maintain oral health correctly with a dental model, images, disclosing solution, toothbrush, and dental floss. ${ }^{3}$ Dentists are also able to give an education regarding oral health individually to a patient in a dental chair, popularly known as the chairside talk. Every patient in a dental practice needs to be 
given an education about plaque control and encouraged to do the oral health care every day. ${ }^{4}$ Sustainable and adequate personal oral health is the best guarantee for periodontal health. ${ }^{5}$ With the implementation of chairside talk, dentists are able to give an education to a patient individually to increase their knowledge and awareness about their oral hygiene.

A standard of the dental education program by Indonesia Medical Council stated that the graduate medical professional students (residents) need to fulfill the competency such as the health communication, effective information and education, and responsibility both oral and written, towards the patient, patient's family or guardian, and the community. The guidelines for the implementation of undergraduate education and graduate medical professional program in Faculty of Dentistry Universitas Padjadjaran also required all students to know the health education concept, the role of health education in health programs, health education components, and methods and supporting instrument for health education. The residents also have a duty, like every other professional dentist, to give an education and oral health promotion, one of them is education regarding the plaque control.

Based on the description above, this research was aimed to observed the implementation of the chairside talk regarding the plaque control instruction by Periodontics Residents at Periodontics Clinics of Faculty of Dentistry Universitas Padjadjaran Dental Hospital.

\section{METHODS}

This study was a descriptive study with survey methods. The population of this study was all of the graduate medical periodontics professional program students (residents) at Periodontics Clinics of Periodontics Clinics of Faculty of Dentistry Universitas Padjadjaran Dental Hospital, with criteria as follows: the second and third-semester residents; willing to be observed while doing the plaque control instruction.

The sample was chosen by the simple random sampling system. In simple random sampling technique, the desired sample was chosen randomly. ${ }^{6}$ The data was collected by explaining to the respondent about the intention and aim of this study, and respondent's permission of observation while the chairside talk regarding the plaque control instruction was performed was asked, and all of the observation results were written in a checklist paper. This study was conducted from April to August 2011.

The implementation of the chairside talk regarding the plaque control instruction was included: the way of communication (how the residents were conveying information regarding the patient's plaque control instructions); the use of props (tools used by residents to assisted the process of delivering the control plaque instructions to the patients); materials delivered (materials on the instruction of control plaque given).

\section{RESULTS}

The results of this study were based on the observation of the implementation of the chairside talk regarding the plaque control instruction by 60 Periodontics Residents at Periodontics Clinics of Faculty of Dentistry Universitas Padjadjaran Dental Hospital. All of the respondents (100\%) were performing the chairside talk regarding the plaque control instruction to every patient (Table 1).

The way of communication aspect was observed through 9 different practices which were as follows: the use of understandable common language by avoiding the use of medical terms; gradual invormation delivery; the use of encouraging and faithful statement; avoiding the use of threatening words; repeated and emphasized important message; ensuring the patient's understanding regarding the information provided; responding the patient's reaction; concluded the information regarding the plaque control given; and encouraged the patient's contribution (asks for explanations or express doubts).

Respondents who used understandable common language by avoiding the use of medical

Table 1. The observation results of the chairside talk

\begin{tabular}{llcc}
\hline \multirow{2}{*}{ No } & \multicolumn{2}{c}{ Procedures } & \multicolumn{2}{c}{ Perform } \\
& & F & $\%$ \\
\hline 1. & Perform the chairside talk & 60 & 100 \\
2. & Did not perform the chairside talk & 0 & 0 \\
\hline
\end{tabular}


terms were as much as $81,67 \%$, as much as $80 \%$ of the respondents who gave the information about plaque control instruction to the patient gradually, respondents who used encouraging and faithful statement when communicating with the patient were as much as $85 \%$, as much as $83.33 \%$ of the respondents were avoiding the use of threatening words, respondents who repeated and emphasized

Table 2. The observation results of the way of communication

\begin{tabular}{lllccc}
\hline \multirow{2}{*}{ No } & \multicolumn{1}{c}{ Procedures } & \multicolumn{2}{c}{ Perform } & \multicolumn{3}{c}{ Did not perform } \\
& & $\mathrm{F}$ & $\%$ & $\mathrm{~F}$ & $\%$ \\
\hline 1 & The use of understandable common language by avoiding the use of medical terms & 49 & 81.67 & 12 & 18.33 \\
2 & Gradual invormation delivery & 48 & 80 & 11 & 20 \\
3 & The use of encouraging and faithful statement & 51 & 85 & 9 & 15 \\
4 & Avoiding the use of threatening words & 50 & 83.33 & 10 & 16.67 \\
5 & Repeated and emphasized important message & 56 & 93.33 & 4 & 6.67 \\
6 & Ensuring the patient's understanding regarding the information provided & 55 & 91.67 & 5 & 8.33 \\
7 & Responding the patient's reaction & 60 & 100 & 0 & 0 \\
8 & Concluded the information regarding the plaque control given & 42 & 70 & 18 & 30 \\
9 & Encouraged the patient's contribution (asks for explanations or express doubts) & 55 & 91.67 & 5 & 8.33 \\
& & Average & 86.3 & 13.7 \\
\hline
\end{tabular}

Table 3. The observation results of the use of props

\begin{tabular}{|c|c|c|c|c|c|}
\hline \multirow{2}{*}{ No } & \multirow{2}{*}{ Procedures } & \multicolumn{2}{|c|}{ Perform } & \multicolumn{2}{|c|}{ Did not perform } \\
\hline & & $\mathbf{F}$ & $\%$ & $\mathbf{F}$ & $\%$ \\
\hline 1 & $\begin{array}{l}\text { Teaching about the proper toothbrushing method and the use of } \\
\text { other oral hygiene instruments using props }\end{array}$ & 22 & 36.67 & 38 & 63.33 \\
\hline 2 & $\begin{array}{l}\text { Teaching about the proper toothbrushing method and the use of } \\
\text { other oral hygiene instruments directly in the patient's mouth }\end{array}$ & 49 & 81.67 & 11 & 18.33 \\
\hline & Average & & 59 & & 40.83 \\
\hline
\end{tabular}

Table 4. The observation results of the materials delivered

\begin{tabular}{|c|c|c|c|c|c|}
\hline \multirow{2}{*}{ No } & \multirow{2}{*}{ Procedures } & \multicolumn{2}{|c|}{ Perform } & \multicolumn{2}{|c|}{ didn't perform } \\
\hline & & $\mathbf{F}$ & $\%$ & $\mathbf{F}$ & $\%$ \\
\hline 1 & Informed the patient regarding the recommended duration of the toothbrushing & 48 & 80 & 12 & 20 \\
\hline 2 & Informed the patient regarding the proper frequency of the toothbrushing & 59 & 98.33 & 1 & 1.67 \\
\hline 3 & Informed their patients the recommended time for toothbrushing & 58 & 96.67 & 2 & 3.33 \\
\hline 4 & $\begin{array}{l}\text { Explained to the patient regarding the proper toothbrushes should used based on the } \\
\text { size, shape, bristle type, etc. }\end{array}$ & 51 & 85 & 9 & 15 \\
\hline 5 & Explaining the proper toothbrushing method to the patient & 60 & 100 & 0 & 0 \\
\hline 6 & Informed the patient the right time to change toothbrush & 30 & 50 & 30 & 50 \\
\hline 7 & $\begin{array}{l}\text { Informed the patient regarding the oral hygiene instruments (dental floss, interproxi- } \\
\text { mal brush, tongue scrapers, etc) }\end{array}$ & 50 & 83.33 & 10 & 16.67 \\
\hline 8 & Explained to the patient on how to use oral hygiene instruments & 41 & 63.33 & 19 & 31.67 \\
\hline 9 & $\begin{array}{l}\text { Informed the patient about the toothpaste ingredients and their function and the rec- } \\
\text { comended toothpaste based on the ingredients function towards the oral health }\end{array}$ & 26 & 43.33 & 34 & 56.67 \\
\hline 10 & $\begin{array}{l}\text { Informed the patient regarding the disclosing solution, along with information on how } \\
\text { to use and its function }\end{array}$ & 44 & 73.33 & 16 & 26.67 \\
\hline 11 & $\begin{array}{l}\text { Explained the patient regarding the effect of toothbrushing and the use of dental } \\
\text { equipment in the wrong way }\end{array}$ & 52 & 86.67 & 8 & 13.33 \\
\hline & Average & & 78,64 & & 21,36 \\
\hline
\end{tabular}


important message while communicating with the patient were as much as $93.33 \%$, as much as $91.67 \%$ of all respondents were ensuring that the patient understands the information provided, all of the respondents $(100 \%)$ were responding the patient's reaction while communicating, as much as $70 \%$ of respondents concluded the information regarding the plaque control given; and respondents who encouraged the patient's contribution (asks for explanations or express doubts) were as much as $91.67 \%$. The observation results on the way of communication aspects was presented in Table 2.

The use of props aspect was observed through 2 different practices which were as follows: teaching about the proper toothbrushing method and the use of other oral hygiene instruments using props; and teaching about the proper toothbrushing method and the use of other oral hygiene instruments directly in the patient's mouth.

Only $36.67 \%$ of respondents were teaching the patient on how to brush their teeth and use other oral hygiene instruments using props, and as much as $81.67 \%$ of respondents were teaching it directly in the patient's mouth, as seen in Table 3.

The materials delivered aspect was observed through 11 different practices which were as follows: informed the patient regarding the recommended duration of the toothbrushing; informed the patient regarding the proper frequency of the toothbrushing; informed their patients the recommended time for toothbrushing; explained to the patient regarding the proper toothbrushes should used; explaining the proper toothbrushing method to the patient; informed the patient the right time to change toothbrush; informed the patient regarding the oral hygiene instruments; explained to the patient on how to use the oral hygiene instruments; informed the patient regarding the toothpaste ingredients and their function; informed the patient regarding the disclosing solution, along with information on how to use and its function; and explained the patient regarding the effect of toothbrushing and the use of dental equipment in the wrong way.

The result of this study showed that as much as $80 \%$ of respondents informed the patient regarding the recommended duration of the toothbrushing, nearly all respondents (98.33\%) informed the patient regarding the proper frequency of the toothbrushing, respondents who informed their patients the recommended time for toothbrushing was as much as $96.67 \%$, as much as $85 \%$ of the respondents explained to the patient regarding toothbrushes should used based on the size, shape, bristle type, etc., all respondents $(100 \%)$ were explaining the proper toothbrushing method to the patient, only half of all respondents $(50 \%)$ were informing the patient the right time to change toothbrush, respondents who informed their patient regarding the oral hygiene instruments and how to use such instruments were as much as $83.33 \%$ and $68.33 \%$ respectively, respondents who informed their patient regarding the toothpaste ingredients and their function were only as much as $43.33 \%$, respondents who informed the patient regarding the disclosing solution, along with information on how to use and its function were as much as $73.33 \%$, and respondents who gave the explanation to the patient regarding the effect of toothbrushing and the use of dental equipment in the wrong way were as much as $86.67 \%$.

\section{DISCUSSION}

All of the respondents (100\%) were performing the chairside talk regarding the plaque control instruction to every patient. Every patient of the dental practice need to be given an education regarding the plaque control instruction and encourage them to do daily oral care. ${ }^{4}$

From the way of communication aspects observed, respondents who used understandable common language and terms by avoiding the use of medical terms was as much as $81,67 \%$. This way of communication was able to increase the patient's understanding of the information provided. The Calgary-Cambridge Guide stated that in order to increase patient's memory and understanding accurately, doctors need to use the concise and understandable common language and terms by avoiding the use of medical terms.

As much as $80 \%$ of the respondents were giving the information about plaque control instruction to the patient gradually. The plaque instruction was given in chronological order to reach the full understanding of the patient. The research conducted by Ley in 1988 stated that separated statement merged into definite part could help the patient more easily to 
remember the given information. This opinion was also consistent with the Calgary-Cambridge Guide stated that doctors need to organize the explanation and divided the information into discrete parts to develop logical sequences. The Calgary-CambridgeGuide also stated that to have an interaction and a two-way transmission when communicating with the patient, doctors need to bring up the patient's faith, reaction, and feeling through the information provided and the terms used.

Respondents who used encouraging and faithful statement when communicating with the patient was as much as $85 \%$. The emergence of patient's faith and spirit when communicates will give a sense of empathy. Empathy can developed if dentists were having the ability to hear and speak, and both should be learned and trained. ${ }^{8}$

When communicating with a patient, most of the respondents $(83.33 \%)$ were avoiding the use of threatening words. The use of threatening words such as "I warn you" or "if you do not follow my instruction, if something goes wrong, do not even think to come back to me" will bring up the patient's anxiety that decreases the communication effectivity. Ley's study in 1988 had stated that if the patient's anxiety level was high, it might lead to the low amount of remembered information. $^{7}$

Respondents who repeated and emphasized important message while communicating with the patient was as much as 56 people $(93.33 \%)$. This repetition intended to increase the patient's understanding of the plaque control instruction given. The Calgary-Cambridge Guide stated that repetition helps the patient's understanding and memorizing every information given. Ley's study in 1988 stated that patients were able to remember the information more if the statement was emphasized as something important.

The result of this study showed that as much as $91.67 \%$ of all respondents were ensuring that the patient understands the information provided. To determine the patient's understanding, doctors usually ask the patient to repeat the information provided. Based on the Calgary-Cambridge Guide, to check the patient's understanding on the information provided (or plans made), doctors could ask the patient to repeat the provided information (or plans made) by their own words.
All of the respondents (100\%) were responding the patient's reaction while communicating. The patient's reaction can be presented in a verbal or non-verbal ways. The Calgary-Cambridge Guide stated that to know the patient's desire and opinion regarding the information provided, and also encouraged interaction with the patient to avoid a one-way transmission, doctors must received and responded towards every verbal and non-verbal cue from the patient. For example, the patient's need to provide their information or asked several questions, stated an excessive information, etc. The balance of the verbal and non-verbal communication will ensure a consistent and unambiguous communication process. ${ }^{7}$

A total of $70 \%$ of respondents concluded the information regarding the plaque control given. Respondents usually concluded the instruction at the end of the chairside-talk implementation after all information was delivered, to make the patient recalls every information given. Ley's study in 1988 mentioned that the statement at the end of the meeting was more likely remembered by the patient (the recency effect). ${ }^{7}$

Respondents who encouraged the patient's contribution (asks for explanations or express doubts) were as much as $91.67 \%$. Respondents usually ask the patient for any incomprehension or questionable information. The patient's contribution will increases their understanding of the information given. Interaction between dentist and patient at the dental practice defined as the achievement of understanding and agreement built by dentists together with the patient at every problem-solving step. ${ }^{8}$

The results of this study showed that only $36.67 \%$ of respondents were teaching the patient on how to brush their teeth and the use other oral hygiene instruments using props like dental models. As much as $81.67 \%$ of respondents were teaching it directly in the patient's mouth. More respondents preferred to teaching the proper toothbrushing method and the use other oral hygiene instruments directly in the patient's mouth because it was more effective. Toothbrushing should be demonstrated in the patient's mouth while the patient was watching through the mirror. Then the patient will have to repeated the procedure on their teeth with the help, correction, and positive support by the oral health instructor/ 
dentists. ${ }^{4}$ This was also consistent with the Edgar Dale's Cone of Experience, where the bottom layer was the original, and showed the highest intensity to perceive educational or teaching materials. This condition means that using real objects in the educational process is the most effective way.

The result of this study showed that as much as $80 \%$ of respondents informed the patient regarding the recommended duration of the toothbrushing. Nearly all respondents $(98.33 \%)$ informed the patient regarding the proper frequency of the toothbrushing. Respondents suggested the patient to brush their teeth, at each buccal, facial, and lingual region, eight times per region, with the total average of 2 minutes. Respondents also advised the patient to brush their teeth twice a day. This suggestion was in accordance with the recommendations of Cancro and Fischman, 9 where toothbrushing was performed twice a day for two minutes. ${ }^{5}$

Respondents who informed their patients the recommended time for toothbrushing was as much as $96.67 \%$. The respondent's recommended time was at the morning after breakfast and at the evening before bedtime. Indonesia Basic Health Research (RISKESDAS) in 2007 categorized the proper toothbrushing habit was the habit of daily toothbrushing with the proper way, that was done at the time after breakfast and before bedtime. ${ }^{1}$

Most of the respondents (85\%) explained to the patient regarding toothbrushes should used based on the size, shape, bristle type, etc. Most respondents only explained that the toothbrush should used was the soft bristled, while only a few of them were giving recommendations about the handle size and the toothbrush head. According to Engelberg and Claffey's study in 1998, there were 5 characteristics of an ideal toothbrush which were the size of the brush handle adjusted with age and the user's skill, the brush head size adjusted to the user's cavity size, a rounded filament of nylon or polyester with both diameters were no greater than 0.009 inches, using soft bristles as defined by international industry standards (ISO), and had a bristle brush pattern allowed to clean the plaque in the approximal part and along the gingival margin. ${ }^{3}$

All respondents (100\%) were explaining the proper toothbrushing method to the patient. Each respondent was teaching the same toothbrushing method which was using a circular motion for posterior teeth, gouging for lingual teeth, oneway brushing for occlusal teeth and vertical movement for facial teeth. This method was a combination of several toothbrushing methods. Studies evaluated the effectiveness of several tooth brushing techniques showed that no method was superior towards other. ${ }^{2}$

Only half of all respondents $(50 \%)$ who informed the patient the right time to change toothbrush. Some respondents asked the patient to bring their toothbrush and notified the patient whether the toothbrush was showing any signs of matting thus unworthy to use. Research conducted by Kreifeldt et al. in 1980 stated that the new toothbrush was more efficient at cleaning plaque than the older one. Therefore, it was recommended to change the toothbrush when it showed signs of matting (bristle hairs look like woven mats), even though the toothbrush has not used for a very long time. ${ }^{3}$

For as much as $83.33 \%$ respondents were informing their patient regarding the oral hygiene instruments such as dental floss, interproximal brush, tongue scrapers, etc. However, only $68.33 \%$ of respondents explained how to use such instruments. Respondents did not explain how to use the oral hygiene instrument due to unavailability of such instruments as the model when the respondent gave the patient plaque control instructions. The respondent described only dental floss and tongue scraper. A review by Warren and Chater in 1996 regarding the method for cleaning up interdental parts concluded that all oral hygiene instruments were effective, but the method of use should be appropriate towards each patient and adjusted with the patient's oral condition. $^{3}$

Respondents who informed their patient about the toothpaste ingredients and their function were only as much as $43.33 \%$. Most other respondents were simply just asked the brand of toothpaste used by the patient without asking whether it contained fluoride or explaining the function of fluoride. Patients were supposed to know that the toothpaste used should contain fluoride based on the function of fluoride, especially patients who come to the periodontics clinic because in general, many patients were having periodontal problems. Toothpaste 
containing fluoride is an important part of any long-term control plaque program. Patients with periodontal abnormalities required appropriate use of topical fluoride in the daily control plaque practices to protect and remineralize the radicular surface and dental crown. ${ }^{10}$

The results of this study showed that respondents who informed the patient regarding the disclosing solution, along with information on how to use and its function were as much as $73.33 \%$, while $26.67 \%$ of all respondents were only explained about how to use the disclosing agent without explaining its function. Disclosing solution is used to see the plaque presence on the tooth surface. If it were used before the tooth brushing, the patient would be able to see the amount of plaque formed after the last toothbrushing, as a feedback to the patient regarding their plaque control. ${ }^{5}$

The majority of the respondent $(86.67 \%)$ was explaining the patient regarding the effect of toothbrushing and the use of dental equipment in the wrong way. The effects included the gingival recession and tooth abrasion. Abrasion at the cervical part of the tooth has many etiologies, but most of the cases caused by brushing teeth too often and an excessive pressure of a toothbrush. ${ }^{5}$

\section{CONCLUSION}

All of the graduate medical periodontics professional program students (residents) at Periodontics Clinics of Periodontics Clinics of Faculty of Dentistry Universitas Padjadjaran Dental Hospitalwere performing the chairside talk regarding the plaque control instruction, and most of them were already doing a good communication with the patient in accordance to the literature, teach the patient on how to brush their teeth directly, and give the patient the comprehensive plaque control instruction.

\section{REFERENCES}

1. National Institute of Health Research and Development (NIHRD). Indonesia Basic Health Research (RISKESDAS) 2007-2008. Jakarta: Ministry of Health Republic of Indonesia; 2008.

2. Notoatmodjo S. Metodologi penelitian kesehatan. Jakarta: Rineka Cipta; 2005.

3. Jessri M, Fatemitabar SA. Implication of Ethical Principles in Chair-Side Dentistry. Iran J Allergy Asthma Immunol. February 2007;6(Suppl. 5):53-9.

4. Newman MG, Takei HH, Carranza FA. Carranza's Clinical Periodontology. $10^{\text {th }}$ ed. Philadelphia: Saunders-Elsevier; 2006. p. 729, 733, 742, 744.

5. Lindhe J. Clinical Periodontology and Implant Dentistry. $4^{\text {th }}$ ed. Hoboken: Blackwell Publishing; 2003. p. 450, 452-4, 459-60.

6. Nazir M. Metode penelitian. Jakarta: Ghalia Indonesia; 2009.

7. Humphris G, Ling MS. Behavioural Science for Dentistry. London: Churchill Livingstone; 2000. p. 56, 58, 118.

8. Indonesian Medical Council. Komunikasi Efektif Dokter-Pasien. $1^{\text {st }}$ ed. Jakarta: Indonesian Medical Council; 2006. p. 4, 8, 12.

9. Cancro LP, Fischman SL. The expected effect on oral health of dental plaque control through mechanical removal. Periodontol 2000. 1995 Jun;8:60-74.

10. Newman MG, Takei HH, Carranza FA. Carranza's Clinical Periodontology. 9th ed. Philadelphia: Saunders-Elsevier; 2002. p. 660, 666-7. 